\begin{tabular}{c} 
Volume and Issues Obtainable at Center for Sustainability Research and Consultancy \\
Journal of Business and Social Review in Emerging Economies \\
ISSN: 2519-089X (E): 2519-0326 \\
Volume 6: Issue 2 June 2020 \\
JSRᄃ \\
Journal homepage: www.publishing.globalcsrc.org/jbsee \\
\hline
\end{tabular}

\title{
Role of Perception of Politics in Enhancing Organizational Dissent: Case of Pakistan Telecom Sector
}

\author{
${ }^{1}$ Saman Naz, ${ }^{2}$ Dr. Moeed Ahmad Sandhu \\ ${ }^{1}$ Lecturer, Institute of Management Sciences Bahauddin Zakariya University Multan, Pakistan, \\ saman_naz19@yahoomail.com \\ ${ }^{2}$ Assistant Professor, Institute of Management Sciences Bahauddin Zakariya University Multan, \\ Pakistan, sandhu@bzu.edu.pk
}

\begin{tabular}{l}
\hline ARTICLE DETAILS \\
\hline History \\
Revised format: May 2020 \\
Available Online: June 2020 \\
\\
\hline Keywords \\
Organizational Dissent, \\
Perception of Politics, Self \\
enhancement Motives, \\
Telecom Sector, Pakistan \\
\hline
\end{tabular}

JEL Classification

MO, M12

OPEN ACCESS

\begin{abstract}
The prime objective of the study is to examine the impact of perception of politics on organizational dissent. Moreover, mediating role of self enhancement was examined as well. The data of the study was collected from the employees of the telecom sector through random sampling. For this research, survey method was found to be more suitable involving questionnaire as a data collection instrument. Thus, the present study employed SEM-PLS, which is used to carry out hypothesis testing and the statistical and numerical analysis. The findings of the study revealed that Perception of politics and self enhancement motives significantly impacts organizational dissent. Moreover, mediating role of self enhancement motive also proved to be significant. The findings of the study are important for the academicians and policy makers of HR department in telecom sector of Pakistan.
\end{abstract}

(C) 2020 The authors, under a Creative Commons AttributionNonCommercial 4.0

Corresponding author's email address: saman_naz19@yahoomail.com

Recommended citation: Naz, S. and Sandhu, M. A. (2020). Role of Perception of Politics in enhancing Organizational Dissent: Case of Pakistan Telecom Sector. Journal of Business and Social Review in Emerging Economies, 6(2), 807-819

\section{Introduction}

This is the era of intense competition in which organizations are a lot of difficulties to retain the employees. Retention of employees is very important for the organizations to maximize their profit. Retention of employees becomes very difficult due to the situation of organizational dissent. Basically, organizational dissent is the situation in which there exist disagreement among employee and employer. This disagreement can be regarding the operations, policies and practices of the organization. In the situation of disagreement, the performance of employee is impacted especially, which impacts the overall performance of organization (Nasir \& Mahmood, 2016).

There are three types of dissent that are commonly referred to in the literature based on the strategies used and audiences targeted by the dissenters. These types include articulated dissent, latent dissent, and displaced dissent. Articulated dissent occurs when employees express dissent openly and clearly to 
organizational audiences who can make change happen in the organization; that is, to top management or to supervisors. Latent or lateral dissent occurs when employees express dissent to "ineffectual audiences" within the organization; that is, to audiences that do not have the power or authority to make change happen, such as co-workers and lower-level managers. The last type of dissent is Displaced dissent which occurs when employees express their dissent to external audiences other than media or powerful audiences targeted by whistle blowers (Bouda, 2015).

Perception of employees regarding politics in the organization is the cause of organizational dissent. Moreover, perception of politics is a major cause of employee turnover as a cause of organizational dissent. If the employee who is trained, leave the organization, it impacts the performance in short as well as long run basis. Politics is such kind of self-service behavior in which a person who are playing politics in the organization, having potential to threaten others interest for the sake of his/her interest or goal. This type of politics can create the conflicts and chaos in the organization. So, conflicts have negative effects and having harmful outcomes for employees as well as for the organization (Ullah, Hasnain, Khalid, \& Aslam, 2019).

Telcom sector is the backbone of any country in terms of communication. Moreover, it contributes majorly in the GDP of the country. Same major role is played by the telecom sector in Pakistan. The telecom sector is one of the fastest growing segments of Pakistan's economy and is a key driver for growth. There are an estimated more than 100 Million cellular users and the sector directly or indirectly employs approximately 1.36 Million people. In this scenario, it is very important for the telecom operators to minimize organizational dissent among the employees working there (Kanwal, Ahmad, Majid, \& Nadeem, 2014). Therefore, main objective is the examination of the influence of perception of politics on organizational dissent. Moreover, mediating role of self enhancement will be examined as well.

\section{Literature Review}

\subsection{Organizational Dissent}

It is "expressing disagreement or contradictory opinions about organizational practices, policies, and operations" (Kassing, 2000). The definition emphasizes three aspects: dissent should be expressed, it should involve the discussion of disagreement or contradictory opinions, and dissent might be about organizational policies, practices or operations. Expressing dissent is of great importance and consequences. Research studies have stated, "The expression of dissent in an organization can be conceptualized as a moral obligation, a political right, an enlightened management practice, a minor inconvenience, or a punishable violation of loyalty". Among all the organizational dissent studies, the employee dissent model developed by Kassing (1997) has received particularly great attention from scholars (Kassing \& Armstrong, 2001).

Different definitions of organizational dissent have been given in the literature including the etymology of the word dissent, the different types of dissent, and the differences between dissent and other similar concepts. Etymologically, the term dissent derives from the Latin word dissentere with dis meaning "apart" and sentire meaning "felling" (Kassing \& Armstrong, 2001). Thus, organizational dissent can be defined etymologically as feeling apart from one's organization; that is, not identifying oneself or keeping distance with one's organization. In that sense, the dissenter disagrees with the organization one way or another. Another common definition that goes along with and completes the etymology of the word is the one that Kassing and Avtgis (1999) provided. He defined dissent as not only feeling apart from one's organization but also "Expressing disagreement or contradictory opinions about organizational practices, policies, and operations". This definition creates three conditions for dissent according to Kassing and Armstrong (2001), 1) organizational dissent should be expressed to someone/an audience who is in the organization or outside the organization; 2) the expression of organizational dissent must involve disagreement and contradictory opinions; and 3) the disagreement or contradictory opinions might be against organizational policies, practices, and operations. 
To better understand organizational dissent, previous research has compared it to other similar concepts and found both similarities and differences. For example, it is argued that organizational dissent has been mistakenly used as a synonym of whistleblowing and employee voice, but it is not. Kassing (2001) supported again that organization dissent is no way the same as organizational conflict, upward influence, employee resistance, employee voice, or whistleblowing. He explained that in fact, organizational dissent can be part of or lead to organizational conflict; it may be expressed as part of upward influence. It is a form of employee resistance, a subset of employee voice, and a parent of whistleblowing because the latter is a specific and extreme type of organizational dissent.

In a nutshell, organizational dissent is commonly defined as being distanced from one's organization, expressing disagreement and contradiction in opinions regarding organizational policies, practices, and operations. Although it is not the only definition of organizational dissent found in previous research, this above-mentioned definition has been widely used in previous studies for understanding the issue and will be used here as a working definition for this research project (Alniacik, 2019).

There are three types of dissent that are commonly referred to in the literature based on the strategies used and audiences targeted by the dissenters. These types include articulated dissent, latent dissent, and displaced dissent. Articulated dissent occurs when employees express dissent openly and clearly to organizational audiences who can make change happen in the organization; that is, to top management or to supervisors. Latent or lateral dissent occurs when employees express diss ent to "ineffectual audiences" within the organization; that is, to audiences that do not have the power or authority to make change happen, such as co-workers and lower-level managers. This type of dissent is illustrated in Gossett and Kilker (2006) case study on counter-institutional websites. They found that employee's resort to informal networks, such as websites and online forums, to express their gripes and complaints and to share information when attempts to use official dissenting channels fail or are not encouraged by the organizations. The last type of dissent is Displaced dissent which occurs when employees express their dissent to external audiences other than media or powerful audiences targeted by whistle blowers. With this strategy, dissenters express their frustration to audiences who are less likely to take action for change, including family members, non-work friends, partners, strangers, etc.

Self-Enhancement is generally regarded as an ego-defense mechanism, where self-favoring judgments are made to protect one's ego and self-esteem against undesirable thoughts (Dierckx, 2017). In line with this idea, Wojcik, Hovasapian, Graham, Motyl, and Ditto (2015) proposed a theoretical mediationmodel, in which political conservatism exerts an influence on self-reported organizational dissent, through threat and SE. So according to these authors, conservatives' proneness to negativity and vulnerability to threatening issues induces the need to protect one's self-esteem (Hibbing, Smith, \& Alford, 2014).

\subsection{Perception of Politics}

One of the most important and descriptive terms that is used within the organization which is related to the behaviors of the employees is "politics". It can be depicted as inter-personal behavior presented to increase individual's interest at expense of others. Organizational politics is a reality of life at the workplace. Furthermore, it includes voluntary activities to meet personal rather than organizational goals (Johnson, Rogers, Stewart, David, \& Witt, 2017). Additionally, it may be in favor or against the interest of an organization depending on the situation but mostly it is considered detrimental as it has the potential to reduce the organization's efficiency and effectiveness.

Moreover, it also restricts information sharing thus creating communication barriers. An organization, which is dominated by politics, is very stressful for employees to work in, ultimately resulting in high turnover (Sultan, Kanwal, \& Gul, 2015). Therefore, organization politics creates negative perception in the mind of employees where employees think political activities surroundings by them which may cause harmfulness. On the basis of above information, POP is defined as the extent to which employees 
think about political activities in the organization. Since, organizational politics involves self-acting political activities that are not endorsed by the organization. From two decades, it is perceived as having negative effects on organizational performance. Politics is such kind of self-service behavior in which a person who are playing politics in the organization, having potential to threaten others interest for the sake of his/her interest or goal. This type of politics can create the conflicts and chaos in the organization. So, conflicts negatively effects and having dangerous outcomes for employees also for the business (Chang, Rosen, Siemieniec, \& Johnson, 2012).

Organizations in which employees perceive higher organizational politics have high turnover rates as compared to those that have a friendly working climate. Employees who are working in an environment where political activities exists, those employees may be physically good but mentally they are affected by the political activities of the surrounding which damages their well-being and performance in the organization. Miller, Rutherford, and Kolodinsky (2008) proposed that the POP leads to negative concerns and intention towards employees that may decide to leave the organization. So, politics in an organization may cause the reduction in organization performance and also human capital.

Luqman, Javaid, and Umair (2015) characterized perception of politics (POP) as the utilization of influence to acquire favors that are not approved by the organization or to get genuine supports through unapproved implies. Organizational politics happens, when individuals exploit associations for the sole motivation behind augmenting personal interest. This is an inescapable component of workplace. An individual must perceive and handle its essence, and thusly, explore its minefield with the end goal to succeed and viably achieve work ventures. On the off chance that a specialist denies or disregards the "bad politics" (e.g. preference) that may happen around him or her, one may absurdly lament while others take out of line advantage. The limited condition of assets makes pressure ascend among laborer as they contend to accomplish their necessities and organizational targets. Be that as it may, rather than being latent and sad, an IWE (Islamic work ethics) laborer would rehearse "great politics" so he or she doesn't botch chances to facilitate legitimately both individual achievement and that of the group. An IWE laborer would pursue Islamic work lessons that incorporate regard, benevolence, unwaveringness, balance, resistance, collaboration, and work dedication (i.e. "great politics") with the end goal to "support" him or herself from "terrible politics." If a laborer has the correct disposition and conduct, at that point his or her work practices won't be addressed. Thusly, one would make progress at work that may absolutely convert into employment fulfilment and satisfaction. An IWE laborer realizes exceptionally well that work in Islam isn't just a method for sustenance, yet in addition a commitment, obligation, and wellspring of social satisfaction and psychological joy. Most researchers discovered politics to impact adversely work demeanor and execution. Different researchers analyzed distinctive indicators of politics utilized by ground-breaking bosses (Meisler \& Vigoda-Gadot, 2014).

Politics is an unavoidable reality of organizational environment, persevering as a prime region of enthusiasm for the two scholastics and specialists. It is just defined in more appropriate way Farmer and Van Dyne (2017), representatives' perceptions of organizational politics (POPs) remain particularly deprecatory, prove by recorded negative relationship with mentalities, practices, and results. For instance, research outline shown that such perceptions have solid positive associations with stress and throughput aims and solid, negative associations with employment fulfilment and full of feeling responsibility (Landells \& Albrecht, 2019).

It is proposed that politics in an organizational workplace is extremely detrimental to the employee's behavior towards positive work, especially when the same political behavior is being observed by everybody in the company. Under the scope of this lens, several analyses and primary studies have proposed a negative correlation of the organizational politics to the individual's behavior which in turn is associated with the effectiveness of the organization in maintaining competitive advantage (Brouer, Harris, \& Kacmar, 2011). 
Since organizational politics is an unavoidable consequence of any workplace, and because it is almost always negatively associated with the work efficiency, researches have set themselves on a journey to answer why the perception of organizational politics has such detrimental effects. Over the years of consequent research, opposing camps of such researchers have proposed contrasting reasons for negative effects of perceiving departmental politics. One paradigm suggests that practice of politics in any organizational is intrinsically stressful to an employee (termed as stressor paradigm) while the others are of the view that departmental politics negatively affects the relationship of an employee to its parent organization, thus reducing the work efficiency (termed as exchange relationship paradigm) (Rosen, Harris, \& Kacmar, 2009).

Although both paradigms (stressor and exchange relationship) have evolved independently of each other, close examination of the literature concerning both has revealed common theoretical foundations. More specifically, both paradigms agree that organizational politics modulate an individual's psychological needs vital for the primary well-being of any person (Ryan 1995), which consequently is detrimental to the quality of relationship being perceived by an employee to its organization which then ultimately forces an individual to experience stress (Cropanzano \& Mitchell, 2005).

\subsection{Self-Enhancement Motives: Role as Mediator}

The self is "the totality of interrelated yet distinct psychological phenomena that either underlie, causally interact with, or depend upon reflexive consciousness" (Sedikides \& Gregg, 2008). Such a definition of self looks extremely twisted when observed superficially but it has its merits. It puts stress on the fact that no matter how complex a process or a property is, if it is sufficiently relevant, it can be defined empirically and conceptually. It also glues together self and the real social world. Anyhow, such a definition is indeed unpleasant. This is the very self which any conscious Android data mounted on Star Trek should possess, encrypting, storing and processing actionable information to generate accurate knowledge on the basis of which any action should be taken.

Generally, self-enhancement includes taking a partially favorable perspective of oneself. It is known as the motive of an individual in order to sustain his self-esteem. Self-enhancement is an individual's desire to be positively related to other individuals. It is worthy in the circumstances when the person faces any failure/threat in his professional or personal life. (Djikic, Peterson, \& Zelazo, 2005). Self-enhancement is a sort of self-evaluation when the individuals who are facing any failure/threat focus on his positive self-development. In what pursues, we will attempt to additionally clear up the idea by illustration an allencompassing (and maybe unrealistic) similarity among it and a more recognizable idea: eating. It is done on the grounds that the term self-enhancement can allude to a few marvels that remain needing cautious refinement. Eating is a spurred movement in people; one established in science yet controlled by culture (Kurt \& Paulhus, 2008).

Self-enhancement can be additionally portrayed as fluctuating along a few bipolar measurements. Initial, one can self-improve either independent from anyone else progressing or self-securing it means, either by enlarging the energy or reducing the antagonism of the self-idea or self-esteem. The gastronomic similarity would here be that one can eat to delight individual's sense of taste and also to remove starvation. This arrangement is a subset of broader refinement among methodology and shirking (Elliot \& Mapes, 2005).

Another experimental ramification proves self-insurance as a more dire need than self-headway, provided that, when all is said in done, "bad is more grounded than great" (Baumeister, Bratslavsky, Finkenauer, \& Vohs, 2001). For instance, the disparity between the self-one right now is and the selfone feelings of dread he or she may move toward becoming predicts enthusiastic states superior to anything the error between the self-one at present is and the self-one would in a perfect world like/feels ethically obliged, to be (Heppen \& Ogilvie, 2003). Individual contrasts additionally moderate which system individuals embrace: Those having higher self-esteem organize self-advancement, though those 
having lower self-esteem organize self- protection, with regards to their comparing propensities towards risk chasing or risk avoidance. Second, one can self-improve either freely or secretly. The previous includes a component of positive self-introduction. Though the last is an all the more simply intrapsychic issue. The gastronomic similarity here would be that one can eat either to fulfil cravings for food or out of social good manners. The qualification is experimentally applicable in light of the fact that the nearness of others now and again potentiates self-enhancement and some of the time restrains it. What's more, albeit self-enhancement irrefutably happens in private, social reality might be thoughtfully interjected so self-assessment may in every case verifiably occur in examination with envisioned others (Campbell, Reeder, Sedikides, \& Elliot, 2000).

Third, individuals vary regarding which areas mostly matters to them. Self-enhancement happens primarily in areas that do make a difference as opposed to in those that don't. As William James (1890/1950) put it "I, who for the time have staked my all on being a psychologist, am mortified if others know much more psychology than I. But I am contented to wallow in the grossest ignorance of Greek'. (If we compare, people who crave the food enjoys their food most (Crocker \& Wolfe, 2001).

At last, self-enhancement can be either straight or strategic (Sedikides and Strube, 1997). Showing that an individual can both grab an open door for obvious and prompt self-advancement, or an individual can swear off it for different exercises subject to encourage postponed self enhancement. For instance, one may strategically search out indicative as opposed to complimenting data about oneself to cure lacks or extend capabilities, consequently empowering one to take part in more legitimized and persisting selfenhancement later on (Pyszczynski, Greenberg, \& Goldenberg, 2003). In examination, working up a craving increment ensuing satisfaction in nourishment. Motivation to favor strategic over real selfenhancement is that other individuals for the most part hate seeing the last in plain view. For sure, narcissism can be portrayed as including an incautious inclination for real to life self-enhancement, conceivably in light of an all the more squeezing fundamental rationale to self-upgrade (Sedikides \& Gregg, 2001).

Self-Enhancement is generally regarded as an ego-defense mechanism, where self-favoring judgments are made to protect one's ego and self-esteem against undesirable thoughts. In line with this idea, it is proposed a theoretical mediation-model, in which political conservatism exerts an influence on selfreported organizational dissent, through threat and SE. So according to these authors, conservatives' proneness to negativity and vulnerability to threatening issues induces the need to protect one's selfesteem (Wojcik et al., 2015).

In order to do this, right-wing adherents tend to give positively biased self-descriptions; which in turn distorts their self-reports of productivity and SWL (for a schematic overview of this mediation model). Support for the first part of this hypothesis (conservatism influences SE tendencies through threat) is provided by a number of studies identifying a relationship between threat to self-esteem and SE. Landau and Greenberg (2006) found that the experimental manipulation of factors that posed a threat to selfesteem (such as cognitive load or mortality salience) led to subsequent behaviour and judgments associated with heightened levels of SE.

Corroborating these findings, a meta-analysis by Campbell and Sedikides (1999) of 70 experiments revealed that increasing self-threat augmented the number of attributions of success to internal factors (i.e. 'the Self') and attributions of failure to external factors; whereas decreasing self-threat had the opposite effect. And it is also discovered that the effects of threat load are not limited to a single culture: in their sample, consisting of respondents from 15 countries, socioeconomic inequality co-varied with magnitude of bias in self-perception (Loughnan et al., 2011).

Consistent with the latter part of the mediation model ("inflated SE biases self-reports of organizational dissent, it is established that interpersonal differences in Self-Deceptive Enhancement accounted for variations in SE-biased responding on a 'happier-than-average-scale', and that experimentally 
manipulating the perceived desirability of productivity increased the tendency to obtain higher scores on the SWLS. This challenges the assumption that the relationship between political conservatism and SelfDeceptive Enhancement is driven by threat. Secondly, studies focus solely on Self-Deceptive Enhancement as a potential source of noise in self-reports. responding in questionnaires: SelfMonitoring. We will argue that it can be related to organizational dissent, bias in self-reports and conservatism; and we will propose an alternative, theoretical mediation model accounting for the 'productivity gap' between liberals and conservatives (Wojcik et al., 2015).

Resource Replacement is the model of protection of resources likewise proposes that in spite of the fact that loss of resources is stressful, individuals may utilize different resources to offset net misfortune. Replacement is maximum immediate way this is refined. Likewise, it was discovered that reemployment following delayed joblessness to a great extent neutralizes misfortune related despondency, and nervousness. At the point when coordinate re-position isn't conceivable, emblematic replacement or replacement through aberrant means might be conceivable. Various researches and studies represent, for example, that following loss of confidence individuals endeavor to straightforwardly modify conceivably hurtful conditions with the end goal to encourage constructive criticism (moderately immediate), repay by recovering regard in other related territories (generally roundabout), or misleadingly gain bolster for their coveted identity through shallow interpersonal controls.

Therefore, above discussion shows that there exists the relationship among self enhancement, POP and organizational Dissent. This condition fulfils the mediation condition of Baron and Kenny (1986).

On the basis of above literature, following hypothesis are developed:

H1: POP significantly impact the organizational dissent

$\mathrm{H} 2$ : Self enhancement motive significantly impacts the organizational Dissent

H3: POP significantly impacts the self enhancement motive

H4: Self enhancement mediates the relationship of POP and Organizational dissent,

\section{Research Framework}

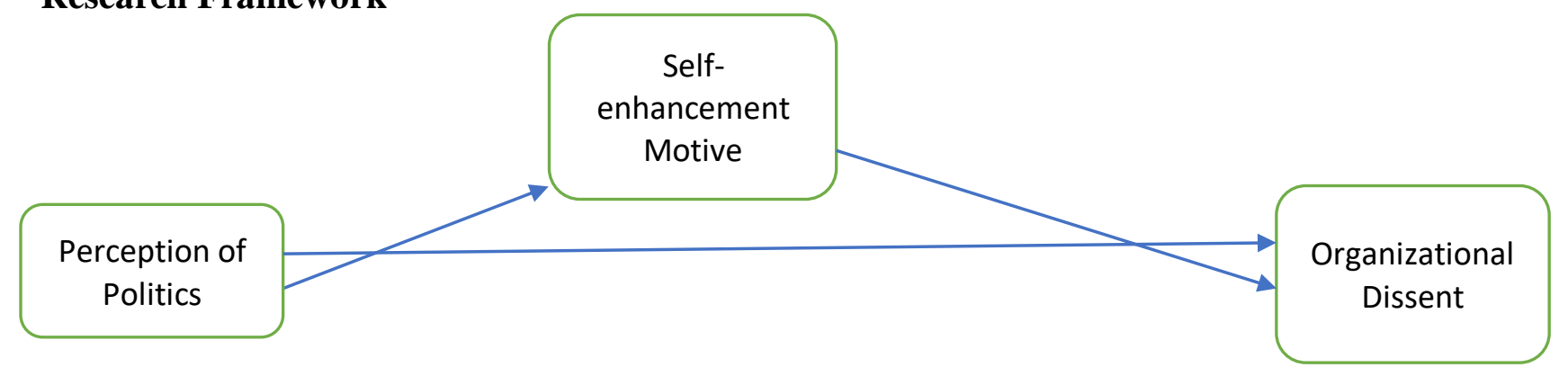

\section{Methodology}

In this research, we used a quantitative cross-sectional design method. In this method the relationship between the variables is quantified. The hypothesis proposed in this research was derived after reviewing the literature and subsequently, a cross-sectional survey was conducted through the random sampling, using a list of questionnaires. A random sample procedure was chosen to explain population through the sample, thereby ascertaining that sample truly reflects the observed population. For this research, survey method was found to be more suitable involving questionnaire as a data collection instrument. Selecting samples from a list of all the observed data involves an arbitrary number selection from the random numbers' table, provided by the program. The firm assigned with the number corresponds to any population firm which is then added into the sample. Meanwhile, a table was generated including 550 random numbers using a random number generator. The data analysis techniques are the statistical tools and procedures which are used by the researcher to analyse data, testing the proposed research hypotheses and refining the theories. For data analysis in this research, the 
Partial Least Square Structural Equation Modeling (PLS-SEM) approach was chosen, which is performed under the assumptions like homoscedasticity, non-multicollinearity, linearity and autocorrelation. These assumptions were followed in this research to ascertain whether these assumptions have been met by the underlying technique. Thus, the present study employed SEM-PLS, which is used to carry out hypothesis testing and the statistical and numerical analysis. A substituting approach for SEM is CSA-SEM which is a covariance structure analysis. CSA-SEM is a popular and the earliest regression-based approach for estimating SEM parameters via minimized covariance matrices. PLS-SEM is a second generation approach that measures the partial model relationships, through variance maximization with the attractive PLS succession. Joe F Hair, Sarstedt, Ringle, and Mena (2012) argued that PLS-SEM application is more pertinent when the multi-variant normality assumption cannot be met completely.

\section{Results}

Subsequent to data checking and screening, the outer and inner models were assessed in the next step. Therefore, for outer and inner models' estimation also known as measurement and structural models, respectively, PLS-SEM was adopted. Putting differently, this study used PLS-SEM for analyzing direct and moderating results obtained in this research. Afterwards, Smart PLS 3.0 was employed for determining the causal associations between the theoretical model constructs (Vinzi, Chin, Henseler, \& Wang, 2010).

PLS model estimation and interpretation involves two phases; in the first phase, the outer model is measured for checking the reliability and validity and in the second phase, the structural model is analyzed through observing the effect size, predictive model relevance, and R-square. The properties for the constructs with multiple items were estimated by incorporating the discriminant and convergent validity in the first phase, followed by the testing of proposed hypotheses through bootstrapping method in the second phase. Prior to the testing of research hypotheses, measurement model was assessed through PLS-SEM following Anderson and Gerbing (1988) recommended phases. By observing the construct's convergent, discriminant and content validity, the construct validity can be established.

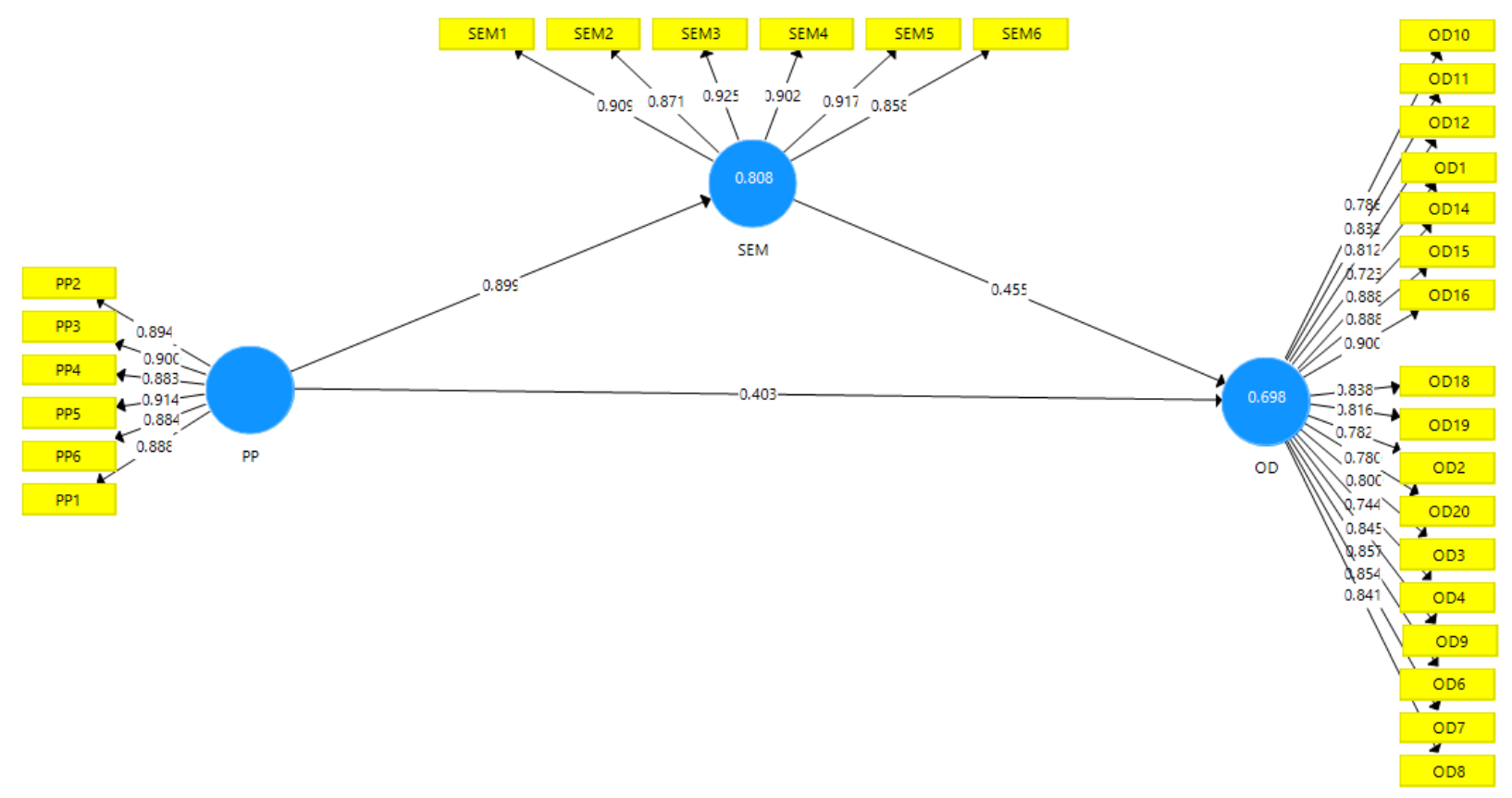

Figure 1: Measurement Model

Joseph F Hair, Black, Babin, and Anderson (2010) defined content and construct validity as the level that the constructs' intended concept is suitably measured by the proposed items. In other words, items 
that are used for measuring the construct must have higher loadings on their respective constructs. Therefore, a detailed literature review was done for considering the items. All the items of the constructs were loaded correctly on their respective constructs based on their factor loadings. Table 1 presents the content validity for the outer model. The table confirms that the factor loadings obtained in this research are the valid number of items thereby ascertaining that content validity is achieved.

Table 1: Outer Loadings

\begin{tabular}{|c|c|c|c|}
\hline & OD & PP & SEM \\
\hline OD1 & 0.723 & & \\
\hline OD10 & 0.786 & & \\
\hline OD11 & 0.832 & & \\
\hline OD12 & 0.812 & & \\
\hline OD14 & 0.888 & & \\
\hline OD15 & 0.888 & & \\
\hline OD16 & 0.900 & & \\
\hline OD18 & $\begin{array}{l}0.838 \\
\end{array}$ & & \\
\hline OD19 & 0.816 & & \\
\hline OD2 & 0.782 & & \\
\hline OD20 & 0.780 & & \\
\hline OD3 & 0.800 & & \\
\hline OD4 & 0.744 & & \\
\hline OD6 & 0.857 & & \\
\hline OD7 & 0.854 & & \\
\hline OD8 & 0.841 & & \\
\hline OD9 & 0.845 & & \\
\hline PP2 & & 0.894 & \\
\hline PP3 & & 0.900 & \\
\hline PP4 & & 0.883 & \\
\hline PP5 & & 0.914 & \\
\hline PP6 & & 0.884 & \\
\hline SEM1 & & & 0.909 \\
\hline SEM2 & & & 0.871 \\
\hline SEM3 & & & 0.925 \\
\hline SEM4 & & & 0.902 \\
\hline SEM5 & & & 0.917 \\
\hline SEM6 & & & 0.858 \\
\hline PP1 & & 0.888 & \\
\hline
\end{tabular}

Convergent validity is the degree that a group of variables come together for measuring a particular concept. According to these researchers, the convergent validity for a model can be determined by testing three important criteria, these are; composite reliability, average variance extracted, and factor loadings. However, the entire set of item loadings were found to be higher than 0.70, which is in 
accordance to the acceptable range suggested by (F. Hair Jr, Sarstedt, Hopkins, \& G. Kuppelwieser, 2014).

Table 2: Reliability

\begin{tabular}{|l|r|r|r|r|}
\hline & Cronbach's Alpha & rho_A & CR & (AVE) \\
\hline OD & 0.970 & 0.973 & 0.973 & 0.679 \\
\hline PP & 0.950 & 0.950 & 0.960 & 0.799 \\
\hline SEM & 0.952 & 0.952 & 0.961 & 0.805 \\
\hline
\end{tabular}

For further validation, establishing the discriminant and construct validity is important. Therefore, discriminant validity is confirmed before testing the hypotheses. Discriminant validity shows the extent that the items characterize the difference between the constructs, indicating non-convergence of the items of different constructs. Moreover, the discriminant validity for the measures' shared variance among each construct must exhibit higher value than shared variance among particular constructs.

Table 3: Validity

\begin{tabular}{|l|r|r|r|}
\hline & OD & PP & SEM \\
\hline OD & 0.824 & & \\
\hline PP & 0.812 & 0.894 & \\
\hline SEM & 0.817 & 0.869 & 0.897 \\
\hline
\end{tabular}

After examining the outer model, the model's validity and reliability are determined followed by assessing the results of the structural model. In this step, the relationship among the constructs and predictive abilities are assessed. It is important to assess collinearity before evaluating the structural model.

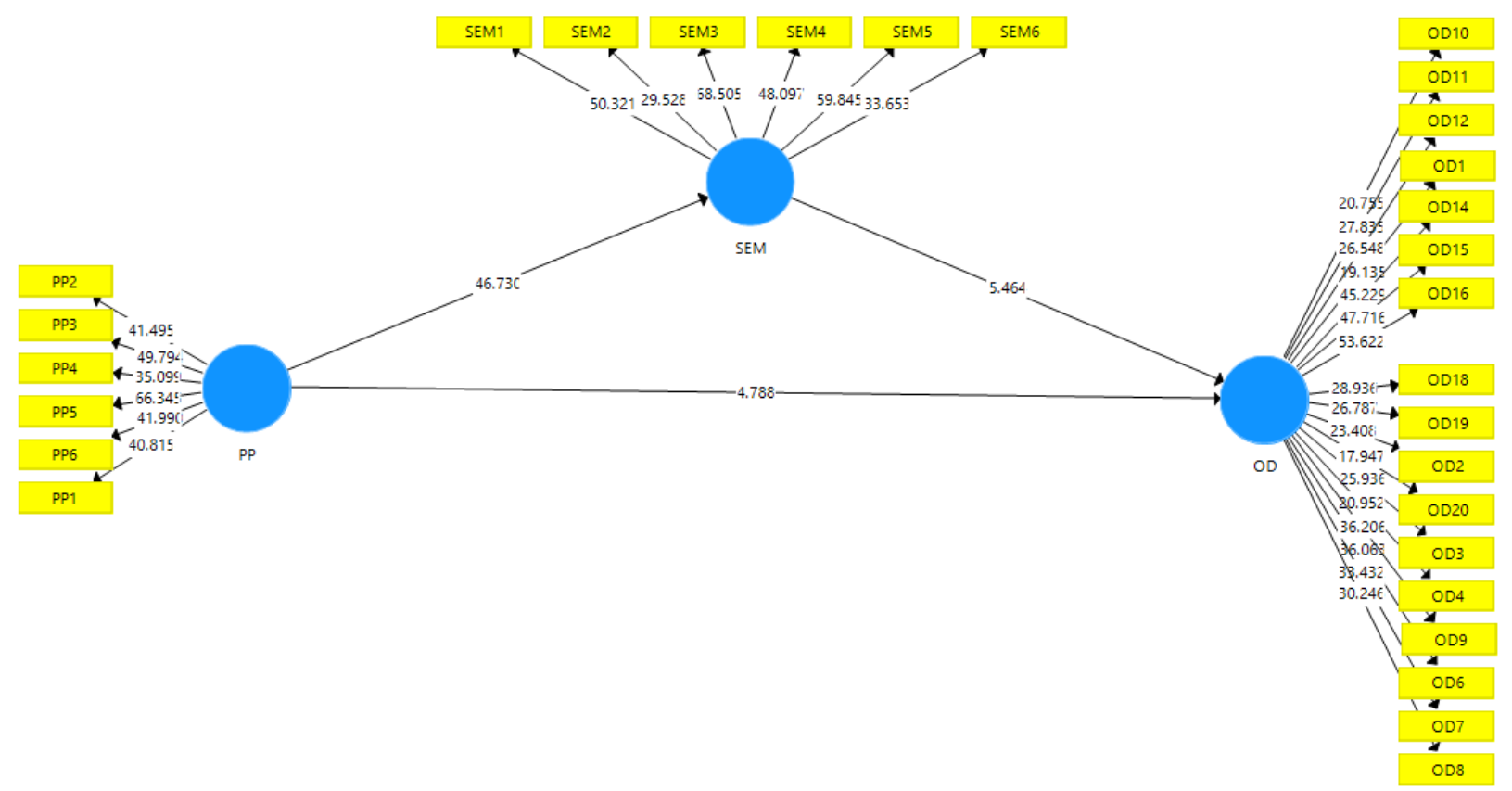

Figure 2: Structural Model

Once the measurement model is determined, the present study then attempted to estimate the inner model. A standard bootstrapping method was then applied in this research with 320 cases and 5000 samples for assessing the path-coefficients' significance. Thus, the statistical significance of path 
coefficients in this study was determined by performing a bootstrapping method using the Smart PLS 3.0. Therefore, for each path coefficients the $t$-values and $p$-values were also obtained. The direct results are shown in the table 4 . The results indicate that all the path is significant at $p$ value less than 0.05 .

Table 4: Direct Relationship

\begin{tabular}{|c|c|c|c|c|c|}
\hline & (O) & (M) & (STDEV) & (|O/STDEV|) & P Values \\
\hline PP -> OD & 0.812 & 0.814 & 0.034 & 24.141 & 0.000 \\
\hline PP -> SEM & 0.899 & 0.899 & 0.019 & 46.730 & 0.000 \\
\hline SEM $>$ OD & 0.455 & 0.461 & 0.083 & 5.464 & 0.000 \\
\hline
\end{tabular}

The results of mediating path are shown in the table 5. The results indicate that the path are significant at $\mathrm{p}$ value less than 0.05 .

Table 5: Mediation

\begin{tabular}{|c|c|c|c|c|c|}
\hline & (O) & (M) & (STDEV) & (|O/STDEV|) & P Values \\
\hline PP $>>$ SEM $>$ OD & 0.409 & 0.415 & 0.078 & 5.253 & 0.000 \\
\hline
\end{tabular}

The predictive ability of any model using SEM-PLS is accessed through the R-square. The R-square value more than 0.15 is considered as acceptable. In our case the values are higher than threshold values as shown on the table 6 below.

Table 6: R-square

\begin{tabular}{|l|ll|}
\hline & R Square & \\
\hline OD & & 0.698 \\
\hline SEM & & 0.808 \\
\hline
\end{tabular}

\section{Conclusion}

This is the era of intense competition in which it is very important for the organizations to retain the employees. In this scenario, it is very important for the organizations to minimize the organizational dissent within the organization. Therefore, main objective was to examine the impact of perception of politics on organizational dissent. Moreover, mediating role of self enhancement will be examined as well. In this research, we used a quantitative cross-sectional design method. In this method the relationship between the variables is quantified. The hypothesis proposed in this research was derived after reviewing the literature and subsequently, a cross-sectional survey was conducted through the random sampling, using a list of questionnaires. A random sample procedure was chosen to explain population through the sample, thereby ascertaining that sample truly reflects the observed population. For this research, survey method was found to be more suitable involving questionnaire as a data collection instrument. The data was collected by the employees of telecom sectors of Pakistan. Thus, the present study employed SEM-PLS, which is used to carry out hypothesis testing and the statistical and numerical analysis. The results show that Perception of Politics has significant impact on organizational dissent. Moreover, self-enhancement motive is also a major contributor of organizational dissent. It also mediates significantly between POP and organizational dissent. The findings of the study are helpful for the policy makers in the HR department of the telecom sector in Pakistan.

\section{References}

Alniacik, E. (2019). Relationship Between Organizational Dissent \& Ethical Climate: Their Effects On Turnover Intentions.

Anderson, J. C., \& Gerbing, D. W. (1988). Structural equation modeling in practice: A review and recommended two-step approach. Psychological bulletin, 103(3), 411. 
Baumeister, R. F., Bratslavsky, E., Finkenauer, C., \& Vohs, K. D. (2001). Bad is stronger than good. Review of general psychology, 5(4), 323-370.

Bouda, D. (2015). The expression of organizational dissent among Sub-Saharan African student migrants in the United States.

Brouer, R. L., Harris, K. J., \& Kacmar, K. M. (2011). The moderating effects of political skill on the perceived politics-outcome relationships. Journal of Organizational Behavior, 32(6), 869-885.

Campbell, W. K., Reeder, G. D., Sedikides, C., \& Elliot, A. J. (2000). Narcissism and comparative selfenhancement strategies. Journal of Research in Personality, 34(3), 329-347.

Chang, C.-H., Rosen, C. C., Siemieniec, G. M., \& Johnson, R. E. (2012). Perceptions of organizational politics and employee citizenship behaviors: Conscientiousness and self-monitoring as moderators. Journal of Business and Psychology, 27(4), 395-406.

Crocker, J., \& Wolfe, C. T. (2001). Contingencies of self-worth. Psychological review, 108(3), 593.

Cropanzano, R., \& Mitchell, M. S. (2005). Social exchange theory: An interdisciplinary review. Journal of management, 31(6), 874-900.

Dierckx, K. (2017). EXPLORING THE MEDIATING ROLE OF SELF-ENHANCEMENT AND SELFMONITORING IN THE 'HAPPINESS'GAP. Ghent University.

Djikic, M., Peterson, J. B., \& Zelazo, P. D. (2005). Attentional biases and memory distortions in selfenhancers. Personality and individual differences, 38(3), 559-568.

Elliot, A. J., \& Mapes, R. R. (2005). Approach-avoidance motivation and self-concept evaluation. On building, defending, and regulating the self: A psychological perspective, 171-196.

F. Hair Jr, J., Sarstedt, M., Hopkins, L., \& G. Kuppelwieser, V. (2014). Partial least squares structural equation modeling (PLS-SEM) An emerging tool in business research. European Business Review, 26(2), 106-121.

Farmer, S. M., \& Van Dyne, L. (2017). Organization-specific prosocial helping identity: Doing and belonging as the basis of "being fully there". Journal of Organizational Behavior, 38(6), 769791.

Gossett, L. M., \& Kilker, J. (2006). My job sucks: Examining counterinstitutional web sites as locations for organizational member voice, dissent, and resistance. Management Communication Quarterly, 20(1), 63-90.

Hair, J. F., Black, W. C., Babin, B. J., \& Anderson, R. E. (2010). Multivariate data analysis: Global edition: Pearson Higher Education Upper Saddle River, NJ.

Hair, J. F., Sarstedt, M., Ringle, C. M., \& Mena, J. A. (2012). An assessment of the use of partial least squares structural equation modeling in marketing research. Journal of the academy of marketing science, 40(3), 414-433.

Heppen, J. B., \& Ogilvie, D. M. (2003). Predicting affect from global self-discrepancies: The dual role of the undesired self. Journal of Social and Clinical Psychology, 22(4), 347-368.

Hibbing, J. R., Smith, K. B., \& Alford, J. R. (2014). Differences in negativity bias underlie variations in political ideology.

Johnson, L. U., Rogers, A., Stewart, R., David, E. M., \& Witt, L. (2017). Effects of politics, emotional stability, and LMX on job dedication. Journal of Leadership \& Organizational Studies, 24(1), 121-130.

Kanwal, A., Ahmad, N., Majid, M., \& Nadeem, M. (2014). The Efficiency of Merger and Acquisition in Telcom Sector of Pakistan. Singaporean Journal of Business, Economics and Management Studies, 51(1122), 1-12.

Kassing, J. W. (2000). Exploring the relationship between workplace freedom of speech, organizational identification, and employee dissent. Communication Research Reports, 17(4), 387-396.

Kassing, J. W. (2001). From the looks of things: Assessing perceptions of organizational dissenters. Management Communication Quarterly, 14(3), 442-470.

Kassing, J. W., \& Armstrong, T. A. (2001). Examining the association of job tenure, employment history, and organizational status with employee dissent. Communication Research Reports, $18(3), 264-273$. 
Kassing, J. W., \& Avtgis, T. A. (1999). Examining the relationship between organizational dissent and aggressive communication. Management Communication Quarterly, 13(1), 100-115.

Kurt, A., \& Paulhus, D. L. (2008). Moderators of the adaptiveness of self-enhancement: Operationalization, motivational domain, adjustment facet, and evaluator. Journal of Research in Personality, 42(4), 839-853.

Landau, M. J., \& Greenberg, J. (2006). Play it safe or go for the gold? A terror management perspective on self-enhancement and self-protective motives in risky decision making. Personality and Social Psychology Bulletin, 32(12), 1633-1645.

Landells, E. M., \& Albrecht, S. L. (2019). Perceived organizational politics, engagement and stress: The mediating influence of meaningful work. Frontiers in psychology, 10, 1612.

Loughnan, S., Kuppens, P., Allik, J., Balazs, K., De Lemus, S., Dumont, K., . . . Matos, L. (2011). Economic inequality is linked to biased self-perception. Psychological science, 22(10), 12541258.

Luqman, M. K., Javaid, M. F., \& Umair, T. (2015). Combined effects of perceived organizational politics and emotional intelligence on job satisfaction and counterproductive work behaviors. European Online Journal of Natural and Social Sciences, 4(4), pp. 891-911.

Meisler, G., \& Vigoda-Gadot, E. (2014). Perceived organizational politics, emotional intelligence and work outcomes: empirical exploration of direct and indirect effects. Personnel Review, 43(1), 116-135.

Miller, B. K., Rutherford, M. A., \& Kolodinsky, R. W. (2008). Perceptions of organizational politics: A meta-analysis of outcomes. Journal of Business and Psychology, 22(3), 209-222.

Nasir, S. Z., \& Mahmood, N. (2016). Determinants of employee retention: An evidence from Pakistan. INTERNATIONAL JOURNAL OF ACADEMIC RESEARCH IN BUSINESS AND SOCIAL SCIENCES, 6(9), 182-194.

Pyszczynski, T., Greenberg, J., \& Goldenberg, J. L. (2003). Freedom versus fear: On the defense, growth, and expansion of the self.

Rosen, C. C., Harris, K. J., \& Kacmar, K. M. (2009). The emotional implications of organizational politics: A process model. Human relations, 62(1), 27-57.

Sedikides, C., \& Gregg, A. P. (2001). Narcissists and feedback: Motivational surfeits and motivational deficits. Psychological Inquiry, 12(4), 237-239.

Sedikides, C., \& Gregg, A. P. (2008). Self-enhancement: Food for thought. Perspectives on Psychological Science, 3(2), 102-116.

Sultan, S., Kanwal, F., \& Gul, S. (2015). Factors of perceived organizational politics: An analysis of what contributes the most? Pakistan Journal of Commerce and Social Sciences (PJCSS), 9(3), 999-1011.

Ullah, S., Hasnain, S. A., Khalid, A., \& Aslam, A. (2019). Effects of Perception of Organizational Politics on Employee's Well-Being: The Mediating Role of Trust and Interpersonal Conflicts. European Online Journal of Natural and Social Sciences: Proceedings, 8(1 (s)), pp. 1-14.

Vinzi, V. E., Chin, W. W., Henseler, J., \& Wang, H. (2010). Handbook of partial least squares (Vol. 201): Springer.

Wojcik, S. P., Hovasapian, A., Graham, J., Motyl, M., \& Ditto, P. H. (2015). Conservatives report, but liberals display, greater happiness. Science, 347(6227), 1243-1246. 